\title{
O PROFESSOR É PRODUTOR DE CONHECIMENTO?
}

\author{
Noely Costa Dias (G-UEMS) \\ Silvane Aparecida de Freitas (UEMS)
}

\begin{abstract}
Resumo
Sabe-se que há muita ausência de embasamento teórico por parte do professor, falta-lhe convicção de que precisa construir seu conhecimento e, consequentemente, elaborar sua própria prática. Diante do exposto, o presente artigo tem por objetivo fazer uma reflexão teórica sobre a formação do professor, seja ele do ensino Fundamental, Médio ou Superior. Tendo em vista que o trabalho do professor, segundo Magnani (1997), não se resume apenas a conteúdos, abrange o desenvolvimento dos modos de pensar, sentir, querer e agir, para que o professor e os alunos possam caminhar na construção do saber, promovendo uma interação entre sujeito (aluno) e objeto (conteúdo) no processo de ensino-aprendizagem. Logo, o professor precisa ter clareza do que pretende e aonde quer chegar para determinar como, onde e quando começar seu trabalho, pois o aluno não é um ser passivo, é um sujeito ativo capaz tanto de assimilar teorias como construir seu conhecimento por meio da reflexão de sua vivência cotidiana.
\end{abstract}

Palavras-chave: Formação de professor. Ensino/aprendizagem. Conhecimento.

\section{Introdução}

Muitos dos nossos professores desenvolvem um trabalho ainda tradicional, reprodutor do sistema que aí está posto, e essa ausência de conhecimento teórico faz com que os professores deixem de produzir seu conhecimento e, consequentemente, de elaborar sua própria prática. Não há reflexão teoria x prática x ação.

Sabe-se que os problemas de aprendizagem são problemas de ensino e de parâmetros estreitos do projeto educativo em que os professores são formados, pois jamais há ensino, se não há aprendizagem; é preciso sempre levar em consideração o processo ensino/aprendizagem e, para isso, o professor precisa ter uma postura diferenciada frente à educação, precisa buscar conhecimentos, fundamentação para tal.

As teorias atuais sobre formação do professor apregoam que o professor e os alunos devem caminhar juntos na construção do saber, construção que se dá por intermédio da realização de pesquisas, análises críticas e reflexão sobre o meio.

\begin{tabular}{|l|l|l|l|l|c|}
\hline Interface da Educ. & Paranaíba & v. 1 & n. 1 & p. 127-139 & 2010 \\
\hline
\end{tabular}


O trabalho do professor, segundo Magnani (1997), não se resume aos conteúdos, mas abrange o desenvolvimento dos modos de pensar, sentir, querer e agir, para que o professor e os alunos possam caminhar na construção do saber, promovendo uma interação entre sujeito (aluno) e objeto (conteúdo) no processo ensino/aprendizagem.

Logo, o professor precisa ter clareza do que pretende e aonde quer chegar para determinar como, onde e quando começar.

Diante do exposto, algumas questões me movem neste artigo: como se dá a formação do professor? Que professor se quer formar? Será que o professor recém- formado em Pedagogia está preparado para assumir uma sala de aula? O que ele realmente necessita na sua formação? A partir destas questões, tenho como objetivo cotejar as ideias de alguns pesquisadores que focalizam a questão da formação de professores, seja ele do ensino Fundamental, Médio ou Superior.

\section{Formação do professor e o processo ensino/aprendizagem}

Iniciaremos nossas reflexões buscando fundamentação na Lei de Diretrizes e Bases da Educação Nacional, Lei n ${ }^{\circ}$ 9.394/96 que nos artigos 61 e 62 estabelece que

[...] a formação de profissionais da educação deverá ter como fundamentos a associação entre teorias e práticas além do aproveitamento da formação e experiências anteriores em instituições de ensino devendo, ainda, esta for mação ocorrer em nível superior, em curso de licenciatura, de graduação plena, em universidades e institutos superiores de educação. Por outro lado, afirma que será 'admitida' como formação mínima o nível médio, na modalidade Normal. (BRASIL, 1996, p. 10).

Isso significa afirmar que a formação do professor tem como objetivo a associação entre as teorias recebidas e práticas aplicadas em sua formação tanto no ensino fundamental, médio e, sobretudo, no superior, sendo este último o essencial para essa formação. Nessa perspectiva, Libâneo (1994) argumenta que:

[...] A atividade de ensinar é vista, comumente, como transmissão da matéria aos alunos, realização de exercícios repetitivos, memorização de definições e fórmulas. O professor 'passa' a matéria, os alunos escutam, respondem o 'interrogatório' do professor para reproduzir o que está no livro didático, praticam o que foi transmitido em exercícios de classe ou tarefas de casa e decoram tudo para a prova.

\begin{tabular}{|l|l|l|l|l|c|}
\hline Interface da Educ. & Paranaíba & v. 1 & n. 1 & p. 127-139 & 2010 \\
\hline
\end{tabular}


Este é o tipo de ensino existente na maioria de nossas escolas, uma forma peculiar e empobrecida do que se acostuma chamar de ensino tradicional. (LIBÂNEO, 1994, p. 78).

No entanto, hoje, espera-se outro tipo de professor, aquele que saia do tradicionalismo e que seja um pesquisador, um produtor de seus próprios conhecimentos, porém, para que ele seja um profissional capacitado, ele precisará investir em sua capacitação e para isso ele teria de ter mais incentivo para isso, ter menos carga horária em sala de aula.

Guedes (2006, p. 19) comenta que a ditadura Militar foi a época em que mais se investiu no professor reprodutor, no seu silenciamento e no do aluno. Começou pelo arrocho salarial, causa e consequência da massificação, que destruiu as condições materiais e intelectuais de trabalho do professor. A quantidade de horas passadas em salas de aula e a quantidade de alunos em cada uma delas desqualificou não só o professor, ao tirar-lhe qualquer tempo para estudo, mas também o aluno, ao impedir o professor de tratá-lo como um indivíduo capaz de contruir uma motivação interior para aprender.

No entanto, ressaltamos que "não há ensino de qualidade nem renovação pedagógica, sem uma adequada formação de profesores" (NÓVOA, 1991 apud KULLOK, 2000, p. 12). Este é o grande desafio da modernidade: investir na formação do professor para que possamos alcançar outro patamar educacional.

Para isso, segundo Martins (2002), necessário se faz a conscientização de que os conhecimentos não são concluídos, prontos e acabados. Esse conhecimento é construído a duras penas; é uma constante buscar de soluções que nunca nos satisfazem, é uma ação x reflexão x ação constantes. Falta também ao professor maturidade e convicção teórica, conscientização política, pois

[...] antes de qualquer consideração específica sobre a atividade de sala de aula, é preciso que se tenha presente que toda e qualquer metodologia de ensino articula uma opção política - que envolve uma teoria da compreensão e interpretação da realidade - com os mecanismos utilizados em sala de aula. (GERALDI, 1997, p. 40).

É necessário que tenhamos a concepção de que a educação é uma prática social.

\begin{tabular}{|l|l|l|l|l|l|}
\hline Interface da Educ. & Paranaíba & v. 1 & n. 1 & p. 127-139 & 2010 \\
\hline
\end{tabular}


Segundo Jobim e Souza \& Kramer (1996, p.14), isso implica entender "o ato educativo de uma forma tão viva como vivo é o seu acontecer, superando as abordagens que dicotomizam trabalho e vida, tomando assim o trabalho como vida e vice-versa".

Segundo esses pesquisadores, é preciso que recuperemos a presença do homem em sua humanidade. O professor e o aluno não podem ser vistos apenas como aquele que ensina e aquele que aprende. Eles são sujeitos históricos. São produtores de linguagem. Linguagem que os constitui como sujeitos humanos e sociais sempre imersos em uma coletividade.

Atualmente, os professores são acusados de quase tudo, isto é, são culpados do fracasso da educação, mas esquecemos que até algum tempo, os professores tinham obrigação apenas com a sala de aula, com o domínio do conteúdo a ser trabalhado com a turma. Nos dias de hoje, as funções desse novo pedagogo passam por uma série de exigências, pois deverá ser capaz de adaptar-se às mudanças, de trabalhar com a criatividade, com o novo, com as novas tecnologias, com a reflexão. E nem sempre esses profissionais da educação estão preparados e, ao invés de se lhe oferecer condições de atualização, resolve-se condená-lo pelo insucesso.

Nota-se que a maioria dos docentes enfreta sua profissão com uma atitude de desilusão e de renúncia, que se tem desenvolvido na medida em que se vem degradando sua imagem social, e assim torna-se um ser desvalorizado perante a outras profissões.

Mesmo assim, em meio a tantas desilusões, segundo Martins (2002), há momentos em que o professor faz algumas opções pedagógicas. Nesse momento, a escolha não é apenas técnica; é, acima de tudo, política, pois nela está implícito o tipo de aluno que se deseja formar e a que sociedade quererá servir. A escolha da prática pedagógica está vinculada à maneira de se ver o mundo, de conceber a sociedade e de querer contribuir: ou para a perpetuação da ideologia dominante, ou para a busca de transformação dessa sociedade.

Segundo essa pesquisadora, a insegurança torna-se maior no início da vida profissional. Como um professor recém-formado, pleno de teorias, poderá transformá-las em práticas inovadoras em sala de aula? E diante de tantas teorias, qual é a melhor opção para o aluno? Como ir contra o discurso e a prática dominantes em nossas escolas? Qual a sua autoridade perante o sistema que aí está legitimado? Conseguirá ter voz? Até que ponto o saber de alguém que ainda não tem experiência em serviço será considerado?

\begin{tabular}{|l|l|l|l|l|c|}
\hline Interface da Educ. & Paranaíba & v. 1 & n. 1 & p. 127-139 & 2010 \\
\hline
\end{tabular}


Hoje exige-se, segundo Kullok (2000, p. 14), que além de saber a matéria que leciona, o professor seja falicitador da aprendizagem, mediador, pedagogo eficaz, organizador do trabalho de grupo, e que, para além do ensino, cuide do equilíbrio psicológico e afetivo dos alunos, da integração social e da educação sexual.

Por isso, a formação deve estimular uma perspectiva crítico-reflexiva, que forneça aos professores os meios de um pensamento autônomo e que facilite as dinâmicas de autoformação participada. Estar em formação implica um investimento pessoal tendo em vista a contrução de sua identidade, que é também uma identidade profissional (NÓVOA, 1995 apud KULLOK, 2000, p. 15-16).

Já para Libâneo (1994, p. 27), a formação profissional do professor compõe-se de um conjunto de disciplinas coordenadas e articuladas entre si, cujos conteúdos devem confluir para uma unidade teórico-metodológica do curso. Essa formação profissional é um processo pedagógico, intencional e organizado, de preparação teórico-científica e técnica do professor para dirigir competentemente o processo de ensino/aprendizagem. É uma ação x reflexão x ação, ou uma atitude que parte da prática vai para teoria e retorna à pratica.

Nesse sentido, defendemos o princípio de que o compromisso social do professor estará alicerçado na sua convicção e na maturidade teórica, no desejo de busca de conhecimentos teóricos para alicerçar sua prática. Assim, ele poderá ter mais subsídios sobre o quê, para quê, para quem e como ensinar.

Por isso Demo (2006) afirma que o professor tem que ser um pesquisador, pois só a partir daí, ele poderá ser um produtor de seus próprios conhecimentos, mas para isso será preciso rever alguns conceitos, tais como ele cita:

[...] O conceito de pesquisa leva a dizer que a avaliação do aluno precisa ser radicalmente revista, para ser coerente com o desafio de gestação do novo mestre. Primeiro, é mister desbancar a prova, que tem seu lugar apenas como expediente esporádico e como acomodação limitativa. Em casos de excesso de alunos, quando é humanamente impossível dedicar-se a número exorbitante de testes, a prova é remédio inevitável, mesmo aquela das respostas fechadas. Entretanto, jamais deveria ser o expediente típico, pois forja situação artificial autoritária e policialesca, motiva a 'cola', força a reproduzir imitativamente as aulas ou leituras caricaturais, leva o aluno a apenas 'estudar para a prova', limitando ou destruindo odesafio de pesquisa e criatividade. (DEMO, 2006, p. 73).

\begin{tabular}{|l|l|l|l|l|c|}
\hline Interface da Educ. & Paranaíba & v. 1 & n. 1 & p. 127-139 & 2010 \\
\hline
\end{tabular}


Não se fala em anular de vez as avaliações, mas de fazê-las de forma diferente, de forma que levem os alunos a exporem seus pensamentos, escreverem, falarem do que realmente aprenderam.

Segundo Guedes (2006), professor é professor: seu compromisso é com alunos indivíduos dotados de disposição interior para aprender - , com a construção do conhecimento desses alunos, com a organização do conteúdo de sua disciplina da forma que lhe parecer adequada para encaminhar essa organização na sociedade. Para isso, é preciso:

\section{[...] deslocar o conteúdo do centro da relação professor-aluno e nele colocar a simpatia, a conscientização, a amizade, o afeto, seja o que for, é o contrário de educar. Professor não é comunicador, porque é muito mais importante quando faz falar do que quando fala. (GUEDES, 2006, p. 25).}

Para que o professor se constitua socialmente como sujeito que domina um certo saber, isto é, o produto do trabalho científico a que tem acesso em sua formação, ele precisará se tornar o próprio produtor de conhecimentos. Pois, se não tiver vontade de busca, de investigar, de ser um pesquisador de sua própria prática, jamais conseguirá ser um ser emancipado, sendo sempre um professor repetidor.

No entanto, para que ocorra emancipação do professor e do aluno, as aulas deverão deixar de ser apenas algo que fique apenas em transmissão de conteúdos e imitação, é preciso que o sujeito possa ter elaborações próprias, ser questionador, criativo. Pois é como Demo (2006, p. 78) argumenta "[...] emancipação é um processo histórico de conquista e exercício da qualidade de ator consciente e produtivo. Trata-se da formação do sujeito capaz de se definir e ocupar espaço próprio, recusando ser reduzido a objeto [...]".

Nesse sentido, Freire (1996, p. 22-23) relata que “[...] o formador é o sujeito em relação a quem me considero o objeto, que ele é o sujeito que me forma e eu, o objeto por ele é formado, me considero como um paciente que recebe os conhecimentos - conteúdos - acumulados pelo sujeito que sabe e que são a mim transferidos [...]." Esse autor ainda acrescenta que "[...] quem forma se forma e re-forma ao formar e quem é formado forma-se e forma ao ser formado. É neste sentido que ensinar não é transferir conhecimentos, conteúdos, nem formar é ação pela qual um sujeito criador dá forma, estilo ou alma a um corpo indeciso e acomodado [...]."

\begin{tabular}{|l|l|l|l|l|c|}
\hline Interface da Educ. & Paranaíba & v. 1 & n. 1 & p. 127-139 & 2010 \\
\hline
\end{tabular}


Portanto, o autor deixa-nos claro o quanto é importante o papel do educador, o quanto tem valor a sua tarefa de docente, e que essa tarefa não é apenas ensinar conteúdos, mas também ensinar a refletir, tornar uma pessoa crítica e não apenas um memorizador. Para Cunha (1994, p. 32), munir-se da pesquisa, significa caminhar para que a educação seja integrada, envolvendo estudantes e professores numa criação do conhecimento comumente partilhado. A pesquisa deve ser usada para colocar o sujeito dos fatos, para que a realidade seja apreendida e não somente reproduzida.

Assim, segundo Smolka (2008, p. 37), a realidade cotidiana escolar e acadêmica e as inúmeras situações de sala de aula como esta são, hoje, resultados ou produtos de um complexo conjunto de condições e circunstâncias em que pesam, obviamente, fatores socioeconômicos, políticos e ideológicos.

Isso porque, na maioria das vezes, o aluno não é visto na escola como alguém que tem vez e voz. Sua alfabetização é cartilhesca, apenas reproduz frases e sílabas, o que lhe acarreta muitas dificuldades em produzir seus próprios textos. Por não ter o quê dizer e para quem dizer em sala de aula, passa ser mais um reprodutor de ideias alheias, não conseguindo expressar seus ideais, seus medos e angústias, porque o que sempre aprendeu, ocorreu para o sistema escolarizado, a prática do ouvir e executar conforme lhe foi passado, não há uma escrita significativa em sala de aula, falta a prática com textos reais, do seu cotidiano. Isso se deve muito à falta de preparo intelectual do professor em investir em sua formação.

Sabemos que a formação continuada do professor se dá em serviço, na busca de mais subsídios para o seu fazer pedagógico, na relação prática $\mathrm{x}$ teoria $\mathrm{x}$ prática. O professor precisa ser um pesquisador, investigar os problemas de sua realidade de sala de aula, não pode ficar esperando as cartilhas dos governos para que possa reproduzir em sala de aula, ou seja, ficar sempre na mesmice, pegar tudo pronto e transferir o que recebe de forma mecânica.

Nesse sentido, a pesquisadora Magnani (1997) argumenta:

Produzindo para outros, aqueles que de fato trabalham, operam com instrumentos e materiais que não produziram, a partir de projetos que não conhecem e de utopias que não são as suas.

\begin{tabular}{|l|l|l|l|l|l|}
\hline Interface da Educ. & Paranaíba & v. 1 & n. 1 & p. 127-139 & 2010 \\
\hline
\end{tabular}


Vistos como mãos ou olhos vigilantes da maquinaria, que geram excedente, esses sujeitos parcelados, cujo ofício foi também parcelado, vão se formando parceladamente, com necessidades de preparação e qualificação inversamente proporcionais ao avanço da ciência e da tecnologia - a serviço ambas dos que controlam concepção e execução - e como fatores de eficiência e rotina racionalizada das operações de produção. Para isso, na grande maioria dos casos, em termos de instrução básica e preparação são suficientes semanas ou meses de treinamento na prática, e a maquinaria se torna 'pelourinho' e 'sucedâneo da competência'. (MAGNANI, 1997, p. 18-19).

Contudo, Magnani (1997) ainda comenta que as exigências de melhores serviços e aprimoramento técnico da prática docente, sob a alegação de crise na educação, configuram-se como uma racionalização dos conflitos gerados nesse processo, pelas permanentes necessidades de ajustamento do modo de produção capitalista, assim como aquelas de constituição de sujeitos e de superação de sua condição de "classe" submissa e coisificada.

Assim sendo, essa autora afirma que

[...] mapeamentos como esses têm levado, muitas vezes, a raciocínios simplistas, ancorados em tendências educacionais reprodutivas ou salvacionistas: a educação é um Aparelho Ideológico do Estado, e, enquanto não se transformarem as condições sociais que a determinam, a escola continuará reproduzindo as relações de dominação capitalista; a escola e o professor têm de despertar o espírito crítico e a consciência revolucionária do aluno, para ele apoderar-se dos conteúdos de ensino como instrumentos de dominação e transformar a sociedade. (MAGNANI, 1997, p. 26).

Para isso, o trabalho do professor não poderá ser uma alienação imposta, dadas as características de seu serviço de ensinar com suas exigências de unidade entre teoria e prática, tendo como instrumento, material e objeto o próprio conhecimento e seus processos de produção social, mas também não sendo apenas divulgador de conhecimento, mas sim de elaborador e organizador de ideias.

Assim sendo, Guedes (1942), afirma que:

[...] O professor acaba sendo, por causa disso, o grande responsável por sua própria formação, e é o seu discernimento na escolha do (s) modelo (s)a imitar que vai dar rumo para o seu trabalho: seleciona, entre os professores teve, modelos de postura em sala de aula, de procedimentos didáticos, de seleção e organização do conteúdo. Ou seja: a formação do professor segue uma degeneração do modelo medieval da corporação de ofício, não é uma presença concreta no processo educativo, e sim uma memória do aprendiz. (GUEDES, 1942, p. 27).

A experiência em sala de aula é que poderá dar-lhe condições de tomar distância desses modelos, à medida que seu trabalho pedagógico vá constituindo sua concepção de estrutura da

\begin{tabular}{|l|c|c|c|c|c|}
\hline Interface da Educ. & Paranaíba & v. 1 & n. 1 & p. 127-139 & 2010 \\
\hline
\end{tabular}


matéria e seus procedimentos didáticos, notará as suas dificuldades, os seus anseios e a busca para soluções emergirá.

Nesse sentido, Magnani (1997) defende o princípio de que “[...] o trabalho do professor: a possibilidade de interferência não só nos conteúdos, mas nos modos de pensar, sentir, querer e agir, organizando transformações [...]”, se dá em serviço. Assim ele estimulará os seus alunos a serem sujeitos emancipados e criadores de seus próprios textos e formadores de sua própria opinião.

Sobre esta questão, Ayres (2007, p. 18-19) argumenta que o professor tem que saber dar respostas a quatro perguntas fundamentais: Por que eu ensino? O que ensinarei? Como ensinarei? A quem ensinarei? Mas a maioria diz: "Ensino porque não tenho nada melhor para fazer.", "Ensino porque, embora o salário não seja tão bom, o emprego é garantido." "Ensino porque passei num concurso e não quis desperdiçá-lo". "Ensino porque foi a única coisa que me restou para fazer". "Ou será que ensino porque tenho convicção de que ensinar é a minha paixão e essa paixão me impulsiona a realizar o meu trabalho da melhor forma possível, contribuindo, assim, para o desenvolvimento de cidadãos conscientes, mais bem preparados para enfrentar a vida".

Nessa perspectiva, Demo (1996, p. 47) afirma que o professor tem de "[...] saber que ensinar não é transferir conhecimento, mas criar as possibilidades para a sua própria produção ou a sua construção [...]". Se todos os professores tiverem essa linha de pensamento, teremos muitos mais produtores do que copiadores. É de suma importância começar a incentivar a fazer pesquisa, pois o aluno e o professor estarão aprendendo juntos.

A autora Martha dos Reis (2003) afirma que em termos metodológicos, professores e alunos devem construir o conhecimento, mediante um processo onde as representações imediatas sobre a realidade que os cerca deve ser o ponto de partida e, consequentemente, de chegada. Essa pesquisadora coloca uma questão a este novo profissional, que é estar sempre a par das últimas descobertas da ciência em sua área de especialidade, para que possa iniciar um trabalho com mais consciência e convicção teórica.

\begin{tabular}{|l|l|l|l|l|c|}
\hline Interface da Educ. & Paranaíba & v. 1 & n. 1 & p. 127-139 & 2010 \\
\hline
\end{tabular}


Ayres (2007, p. 32) faz uma importante observação quando cita que "o bom professor tira proveito desse conhecimento de seus alunos e os utiliza em benefício da aprendizagem, fazendo uso de exemplos e ilustrações que sejam impactantes para cada um deles". Essa afirmação é de suma importância, pois assim é mais fácil prender a atenção e o interesse dos alunos, pois para eles o entendimento do conteúdo acaba ficando mais fácil e assim consegue até argumentar sobre o que está sendo passado.

Muitas pessoas acreditam que o desempenho satisfatório do professor na sala de aula depende de vocação natural ou somente da experiência prática, descartando a teoria, porém o domínio das bases teóricas e científicas permite maior segurança profissional, de modo que o professor ganhe uma base para pensar sua prática e aprimorar sempre mais a qualidade do seu trabalho, pois é mais difícil se não tiver uma linha de pensamento, porque querendo ou não, sempre nos espelhamos em alguém, para nos tornar um bom profissional.

Martha dos Reis (2003) comenta também que a repetição e a memorização de conteúdos; avaliações quantitativas; relação professor $\mathrm{x}$ aluno pautada no autoritarismo, em que o primeiro se coloca como detentor do saber e o segundo precisa apenas receber conteúdos prontos e acabados; ensino sem significação e distante da vida dos educadores, não promovem a formação do sujeito.

Essa autora apregoa que o professor e os alunos devem caminhar juntos na construção do saber, construção que se dá por intermédio da realização de pesquisas, análises críticas e reflexão sobre o meio. O professor deve deixar de dar conceitos prontos para os alunos, e sim, juntos, professores e alunos participarem de um processo de construção do saber.

Assim, verificamos que as teorias atuais do processo ensino/aprendizagem, apresentamnos um novo perfil de aluno, que não pode ser visto como um ser passivo, ele é considerado como sujeito capaz tanto de construir seu conhecimento quanto assimilar os conteúdos formais por meio de sua vivência cotidiana. Com isso, o ensino pautado na transmissão e memorização de conteúdos, que tem o livro didático como fim em si mesmo, formará o aluno passivo, sem voz, que não atua como sujeito de seu conhecimento e de sua própria história.

\begin{tabular}{|l|l|l|l|l|c|}
\hline Interface da Educ. & Paranaíba & v. 1 & n. 1 & p. 127-139 & 2010 \\
\hline
\end{tabular}




\section{Considerações Finais}

Diante do exposto, é preciso ressaltar que a formação dos docentes não ocorre apenas em um único local, mas sim em muitos lugares, tais como: nas Universidades formadoras, nas escolas onde exerce sua profissão e se dá a efetivação concreta da teoria na prática. A formação de professores tem que ser vista como um processo contínuo e não apenas como um somatório de disciplinas específicas e pedagógicas.

Deve ser desde o início do curso de formação e estender-se na experiência profissional, considerando esse professor como um produtor do conhecimento, num processo contínuo de formação, que nunca estará acabado, e nem satisfeito com o que sabe e estará sempre pronto às mudanças que estão sendo exigidas.

\section{[...] Espera-se um 'profissional recriado', muito diferente dos vigentes, capaz de construir um projeto próprio educativo e assistencial, ao mesmo tempo competente cientificamente e participativo politicamente. Agentes lídimos de mudança, com base no saber e na cidadania. Como contrapeso às exigências extremas de trabalho produtivo integral, o ISEP assumiu compromisso de atuar, sem isolamento, com os 'recursos humanos' locais, tais quais são, evitando-se dependências. Por isso o conceito de pesquisa se ajusta a tal expectativa, começando no pré-escolar, como princípio científico e educativo. (DEMO, 2006, p. 116).}

O professor não pode ser apenas alguém que transmite conhecimentos, que muitas vezes são ideias de terceiros, mas sim um pesquisador, aquele que sempre aprende e sempre ressalta a pesquisa como um princípio educativo, transformando-se num produtor de conhecimentos, capaz de motivar o seu aluno à pesquisa.

Vários são os motivos para que se possa tornar um bom professor, tais como: o gostar de ensinar e aprender, gostar do ser humano, a necessidade de transformar a sociedade, transformar mentes, pois como Cunha (2004, p. 128) afirma “[...] Saber teorias é importante, mas é preciso saber aplicá-las à nossa realidade e ainda criar coisas novas de acordo com nossos interesses e recursos $[\ldots] . "$

Portanto espera-se muito desse novo profissional do futuro, mas pouco se faz por ele. Acredito que deva melhorar a sua base salarial para que possa investir mais em curso de preparação, pois a cada dia o governo muda as grades escolares, exige mais e esquece que a

\begin{tabular}{|l|l|l|l|l|c|}
\hline Interface da Educ. & Paranaíba & v. 1 & n. 1 & p. 127-139 & 2010 \\
\hline
\end{tabular}


maioria desses profissionais está saturada, sem tempo para estudo, com maior parte do seu tempo passada em sala de aula e no final de semana ainda leva trabalho para casa.

Ao analisar a situação dos nossos professores-pesquisadores, ainda que de escolas com condições superiores às da média das escolas da rede pública, pode-se levantar uma série de conjecturas sobre o papel da pesquisa e de sua relação com o saber docente. Pode-se perceber que convivem nas escolas estudadas vários tipos e até várias concepções de pesquisa.

Apesar dos limites constatados e da falta de uma política governamental de valorização do curso de formação desse profissional, é preciso reconhecer que há condições para a realização de pesquisas, dentro dos estabelecimentos escolares pesquisados. Mas também é preciso reconhecer a falta de clareza sobre que pesquisa poderia ser considerada indicada, para responder às necessidades sentidas pelos professores e, assim, contribuir para o crescimento do seu saber.

\section{Referências}

AYRES, Antônio Tadeu. Prática pedagógica competente: ampliando os saberes do professor. Petrópolis, RJ: Vozes, 2007.

BRASIL. Lei $n^{\circ}$ 9.394/96: lei de diretrizes e bases da educação nacional. Brasília: MEC, 1996.

CUNHA, Maria Isabel da. O bom professor e sua prática. Campinas, São Paulo: Papirus,2004. p. 09-171.

DEMO, Pedro. Pesquisa: princípio científico e educativo. 12. ed. São Paulo: Cortez, 2006. p-p 09-116.

FREIRE, Paulo. Pedagogia da autonomia: saberes necessários à prática educativa. São Paulo: Paz e Terra, 1996. p. 07-146.

KULLOK, Maisa Gomes Brandão. As exigências da formação do professor na atualidade. Maceió: Edufal, 2000. p. 10-56.

GERALDI, João Wanderley (Org.). O texto na sala de aula. São Paulo: Ática, 1997.

GUEDES, Paulo Coimbra. A formação do professor de português: que língua vamos ensinar. São Paulo: Parábola Editorial, 2006. p. 9-100.

\begin{tabular}{|l|l|l|l|l|l|}
\hline Interface da Educ. & Paranaíba & v. 1 & n. 1 & p. 127-139 & 2010 \\
\hline
\end{tabular}


JOBIM e SOUZA, S. \& KRAMER, S (Org.). Experiência humana, história e pesquisa: um estudo da narrativa, leitura e escrita de professores. In: . História de professores. São Paulo: Ática, 1996. p. 14-52.

LIBÂNEO, José Carlos. Didática. São Paulo: Cortez, 1994.

MAGNANI, Maria do Rosário M. Em sobressaltos: formação de professores. 2. ed. Campinas, SP. UNICAM, 1997. p. 11-33.

MARTINS, Silvane Aparecida de Freitas. O professor iniciante: seu trabalho com o texto na sala de aula. 2002. 261f. Tese (Doutorado em letras), UNESP-Assis, 2002.

REIS, Martha dos. Proposta para ação reflexiva no ensino fundamental e médio. Araraquara: JM Editora, 2003. p. 25-50.

SMOLKA, Ana Luiza Bustamante. A criança na fase inicial da escrita. 12. ed. São Paulo, SP: Cortez, 2008. p. 13-45. 